\title{
Diagnostic role of hysteroscopy in abnormal uterine bleeding: a comparative study of hysteroscopy findings with histopathology from Mysore, South India
}

\author{
Mamatha Shivanagappa*, Vinutha K. Veerabhadrappa, Madhumitha Mahesh
}

Department of Obstetrics and Gynecology, JSS Medical College, JSS Academy of Higher Education and Research (deemed to be University), Mysore, Karnataka, India

Received: 26 December 2018

Accepted: 03 January 2019

\section{*Correspondence:}

Dr. Mamatha Shivanagappa,

E-mail: mamathamahesh106@gmail.com

Copyright: () the author(s), publisher and licensee Medip Academy. This is an open-access article distributed under the terms of the Creative Commons Attribution Non-Commercial License, which permits unrestricted non-commercial use, distribution, and reproduction in any medium, provided the original work is properly cited.

\begin{abstract}
Background: Dilatation and curettage has long been the diagnostic gold standard for abnormal uterine bleeding. However, even a trained gynecological curettes at best $70-80 \%$ of the endometrium. Hysteroscopy is gaining acceptability over other diagnostic technique like dilatation and curettage, hysterosalpingogram and ultrasound. The objective of this study is to find out the role of hysteroscopy in abnormal uterine bleeding and to compare hysteroscopy findings with histopathology.

Methods: Fifty patients in perimenopausal age group with abnormal uterine bleeding attending JSS Medical College and Hospital Mysore, during the period 1999-2001 were studied by diagnostic hysteroscopy followed by dilatation and curettage.

Results: Mean age of the study group was $44.3 \%$ years $( \pm 2.5$ SD). Menorrhagia was the commonest symptom and was found in $68 \%$ of the patients. Diagnostic hysteroscopy identified 23 cases as Normal endometrium, 16 cases as endometrial hyperplasia, 3 cases as atrophic endometrium, 4 cases as endometrial polyp, 4 cases as fibroids. Compared with histopathological findings as definitive diagnosis, hysteroscopy correctly picked up 19 cases of (86.9\%), normal endometrium, 12 cases of hyperplasia (75\%), 3 cases of atrophic endometrium (100\%), 4 cases of polyps $(100 \%)$, and 4 cases of fibroid (100\%).

Conclusions: Hysteroscopy should be considered as a basic and essential diagnostic procedure in the diagnostic work up of abnormal uterine bleeding.
\end{abstract}

Keywords: Dilatation and Curettage, Uterine endoscopy, Uteroscopy

\section{INTRODUCTION}

Of the many disorders of uterus which pose a major health hazard in life of woman, abnormal uterine bleeding poses a major challenge to gynaecologists. Onethird of all gynaecological consultations are because of abnormal uterine bleeding (AUB). ${ }^{1}$ The differential diagnosis of abnormal uterine bleeding is complex, but a systematic approach will result in correct diagnosis. ${ }^{2}$
Dilatation and curettage has long been the diagnostic gold standard for abnormal uterine bleeding. However, even a trained gynecological curettes at best $70-80 \%$ of the endometrium. $^{3}$ Hysteroscopy is the endoscopic visualization of uterine cavity and endocervix.

Hysteroscopy is gaining acceptability over other diagnostic technique like dilatation and curettage, hysterosalpingogram and ultrasound. Studies done by 
various authors on the role of diagnostic hysteroscopy in abnormal uterine bleeding have concluded that it can be used as a basic diagnostic procedure. ${ }^{4,5}$

Also a recent study from India revealed the superior ability of hysteroscopy in evaluating patients with AUB, when compared to $\mathrm{D}$ and $\mathrm{C}$ and ultrasonography. ${ }^{6}$ According to some author, no gynaecologist can be considered fully trained without having access to the technique of hysteroscopy. Some authors in contrast believe that hysteroscopy or not, a tissue diagnosis is essential especially in this litigious world. ${ }^{7}$

Hysteroscopy offers a valuable extension of the gynecologist's armamentarium. It can improve the diagnostic accuracy and can permit better treatment of uterine diseases. After hysteroscopy, the elective surgery of the patient can be planned better. ${ }^{8}$ Diagnostic curettage has been the method of choice to diagnose endometrial abnormalities for many years but hysteroscopy combined with histologic examination subsequently became the "gold standard" for such evaluation. ${ }^{9}$ Hence in view of all the above, this study has been take up.

The study was conducted to study the role of hysteroscopy in the diagnosis of abnormal uterine bleeding in perimenopausal age and to correlate the hysteroscopic findings with histopathology.

\section{METHODS}

\section{Inclusion criteria}

- Fifty patients in perimenopausal age group (40-50 years) presenting with abnormal uterine bleeding to Department of Obstetrics and Gynecology, JSS Medical College and Hospital, Mysore, during the period March 1999 to February 2001 were taken up.

\section{Exclusion criteria}

- Patients with active or recent pelvic inflammatory disease

- Those in menstruation phase

- Those with active uterine bleeding.

- Suspected uterine or cervical malignancy

- Pregnancy/suspected pregnancy complications.
In all cases a detailed history of thorough clinical examination was done.

Routine investigations in all and special investigations in selected cases were performed. Ethical Clearance was obtained from the institutional ethical committee of JSS Medical College. Diagnostic hysteroscopy procedure was performed using 4mm Rigid Storz hysteroscope and $5 \mathrm{~mm}$ sheath. Normal saline was used as distension media. All procedures were done under paracervical block with $1 \%$ lidocaine. Systematic survey-observation of cervix, endocervix, uterine fundus, endometrial cavity, right and left corner and both tubal orifices was carried out. Endometrial biopsy was taken in all patients following hysteroscopy and tissue subjected to histopathological examination.

\section{Statistical analysis}

Categorical and continuous variables are expressed as number (percentage) and mean \pm standard deviation respectively. Chi square was applied to compare categorical variables and student's t test was used to compare parametric continuous variables.

\section{RESULTS}

Maximum number of patients $(34 \%)$ were in the age group of 44-46 years. Minimum number of patients (10\%) were in the age group of 48-50 years. Mean age of the patients was 44.3 years with a standard deviation of 2.5. majority of the patients $(84 \%)$ in the present study has painless uterine bleeding. It is seen that in the present study the most common finding was normal uterine cavity and normal looking endometrium found in $46 \%$ of patients. Hyperplastic endometrium was noted in $32 \%$ of patients. Endometrial polylps were found in $8 \%$ of patients, fibroids in $8 \%$ of patients. Atrophic endometrium was found only in $6 \%$ of patients (Table 1).

Table 1: Hysteroscopy findings.

\begin{tabular}{|l|l|l|}
\hline Hysteroscopy findings & No. of cases & Percentage \\
\hline Normal & 23 & 46 \\
\hline Hyperplastic & 16 & 32 \\
\hline Atrophic & 3 & 6 \\
\hline Polyp & 4 & 8 \\
\hline Fibroid & 4 & 8 \\
\hline
\end{tabular}

Table 2: Relationship of hysteroscopy finding and type of bleeding.

\begin{tabular}{|l|l|l|l|l|l|l|}
\hline Type of bleeding & Normal & Hyperplasia & Polyp & Atrophic & FIB & Total \\
\hline Menorrhagia & 15 & 12 & 3 & 1 & 3 & 34 \\
\hline Polymenorrhagia & 3 & 0 & 1 & 0 & 1 & 5 \\
\hline Metrorrhagia & 2 & 0 & 0 & 0 & 0 & 2 \\
\hline Metrophatia haemorhagica & 2 & 4 & 0 & 0 & 0 & 6 \\
\hline Oligomenorrhea & 1 & 0 & 0 & 2 & 0 & 3 \\
\hline Total & 23 & 16 & 4 & 3 & 4 & 50 \\
\hline
\end{tabular}


Table 3: Combined depiction of hysteroscopy and histopathology.

\begin{tabular}{|c|c|c|c|c|c|c|c|c|}
\hline \multirow{8}{*}{ 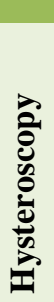 } & \multicolumn{8}{|c|}{ Histopathology } \\
\hline & & Pro & Secre & Hyper & $\mathbf{A T}$ & $\mathbf{F}$ & Polyp & Total \\
\hline & Normal & 10 & 9 & 4 & 0 & 0 & 0 & 23 \\
\hline & Hyperplasia & 3 & 1 & 12 & 0 & 0 & 0 & 16 \\
\hline & Polyp & 0 & 0 & 0 & 0 & 0 & 4 & 4 \\
\hline & Atrophic & 0 & 0 & 0 & 3 & 0 & 0 & 3 \\
\hline & Fibroid & 0 & 0 & 0 & 0 & 4 & 0 & 4 \\
\hline & & 13 & 10 & 16 & 3 & 4 & 4 & 50 \\
\hline
\end{tabular}

Out of 34 patients presenting with menorrhagia, hysteroscopy showed normal endometrium in 15 patients and hyperplastic endometrium in 12 patients. Out of 5 patients who presented with polymenorrhagia hysteroscopy showed normal endometrium in 3 patients (Table 2).

In this study normal endometrium was the commonest finding in patient presenting with menorrhagia, polymenorrhagia and metrorrhagia. The commonest finding in patients presenting with metropathia hemorrhagica was hyperplastic endometrium. Out of 23 cases which had appearance suggestive of normal endometrium by hysteroscopy only 19 were histologically confirmed to be normal and 4 cases diagnosed as normal by hysteroscopy turned out to be endometrial hyperplasia on histopathological examination (Table 3).

Thus, hysteroscopy had a false negativity of $8 \%$ in this aspect. Out of 16 cases endometrium hyperplasia by hysteroscopy only 12 were confirmed histologically. Out of 4 cases which had appearance suggestive of endometrial polyp all 4 were confirmed by histopathological examination. Out of 4 cases which had appearance suggestive of fibroid all 4 were confirmed by histopathological examination. Out of 3 cases which had hysteroscopic appearance suggestive of atrophic endometrium all 3 were confirmed by histopathological examination.

\section{DISCUSSION}

In the present study $84 \%$ of patients had painless bleeding. In Kanakadurgamba's study $84 \%$ had absence of pain. In the study by Joshi $87.5 \%$ cases showed absence of pain. ${ }^{10}$ Since majority of menstrual cycles in perimenopausal age are anovulatory or aleuteal due to waning of ovarian function dysmenorrheal is less common. However, dysmenorrhea may be found in small group of patients with adenomyosis and fibroid.

In the present study group menorrhagia was the commonest mode of presentation $68 \%$. Study by Maheshwari V $(n=104)$ also had menorrhagia as the commonest mode of presentation in $41.3 \%$ of patients. ${ }^{8}$ In study by Sarita Saraiya $(n=85)$ in 1994 menorrhagia was the commonest complaint. Study of Kandeparkar SS $(n=77)$ showed $61.2 \%$ of menorrhagia. ${ }^{8}$ Study by Kathuria R ( $n=50)$ showed $46 \%$ of menorrhagia. ${ }^{11}$ The present study is in agreement with other studies except the study of Kanakadurgamba where only 4\% had menorrhagia. From the comparative table following observations can be seen. Normal cavity was found in $46 \%$ of cases in the present study. This is in agreement with the results of study by Sheth SS and is significant. Similar results have been found in the studies by Neumann T, 55.2\% normal cavity, Mencaglia L, 54\% normal; Bhattacharya BK $34 \%$ normal, Saraiya S $34.1 \%$ normal, Kandeparkar $47 \%$ normal. $^{12}$

In the study by Mohan S, it was concluded by them that hysteroscopy was most useful in predicting normal endometrium. Hence it can be deduced that hysteroscopy by ruling out intrauterine lesions confirms diagnosis of dysfunctional uterine bleeding and aids in proper management. Endometrial hyperplasia was seen in $32 \%$ of case in the present study. This is in agreement with the results of study by Sarita Saraiya 43\%, Sheth SS, $27.4 \%$ Hamou $23.7 \%$.

Fibroid was diagnosed in $8 \%$ of cases. This compares well with the study of Neumann T, $(6 \%)$ and Sarita Saraiya $12 \%$ and Kumaresan $10 \% .{ }^{13}$ In the present study has found in $8 \%$ cases. This correlates with the study by Hamou 9.1\%, Saraiya S, 9.3\%, Sheth SS, 3.9\%, Bhattacharya B K 3\%. Higher incidence of polyps was noted in the studies by Siera $40 \%$, Neumann T $20 \%$.

Regarding the correlation of hysteroscopy and histopathology the following are noted In the present study hysteroscopy and histopathology showed $84 \%$ correlation. This is the agreement with other studies by Kandeparkar SS here $87 \%$ correlation and study by Itzkowic DJ showed a high correlation of $90 \%$. Study of Sarita Saraiya showed $56.5 \%$ correlation. The study of Sheth SS correlation was $55.88 \%$. The study by Raju K S showed good correlation.

The accuracy of hysteroscopy in detecting normal endometrium was $0.9 \%$ and hyperplasia was $75 \%$ and $10 \%$ in detecting atrophic endometrium and $100 \%$ in detecting organic lesions. The overall accuracy of hysteroscopy in the present study was $84 \%$. This is in 
agreement with the study by Baggish et al, $87 \%$ Barbot $84 \%$, Lasala et al, $86 \% .{ }^{14}$ In the study of Frasnis HB hysteroscopy showed $100 \%$ accuracy in diagnosing polyps and fibroid. Mencaglia L et al, in the study concluded that hysteroscopy has $100 \%$ accuracy in diagnosing endometrial hyperplasia, $87.5 \%$ with high risk hyperplasia and $65.2 \%$ with hysteroscopic findings correlate highly with histopathological results Hence hysteroscopy is an invaluable tool providing precise and accurate adjunct to traditional methods of diagnosing intra uterine abnormalities, particularly focal lesions which may be missed at curettage, low risk of hyperplasia.

\section{CONCLUSION}

It is concluded from the present study that hysteroscopy is a procedure with high accuracy, sensitivity and specificity in the diagnostic evaluation of abnormal uterine bleeding. Hysteroscopy by direct visualization of uterine cavity enables either finalization of the diagnosis or defines subsequent course of management Hysteroscopy should be considered as a basic and essential diagnostic procedure in the diagnostic work up of abnormal uterine bleeding.

\section{ACKNOWLEDGMENTS}

Authors would like to thank Dr. Sujatha, MS Professor Department of Obstetrics and Gynecology, JSS Hospital for her overall help and guidance. Authors wish to express their sincere thanks to Dr. Lancy D'Souza, Professor University of Mysore for help in statistical analysis.

Funding: No funding sources Conflict of interest: None declared

Ethical approval: The study was approved by the Institutional Ethics Committee

\section{REFERENCES}

1. Guin G, Sandhu SK, Lele A, Khare S. Hysteroscopy in evaluation of abnormal uterine bleeding. J Obstet Gynecol India. 2011;61(5):546-9.

2. Kistner RW, Ryan KJ, Berkowitz RS, Barbieri RL. Kistner's gynecology: Principles and practice. Mosby Inc; 1995.

3. Word B, Gravlee LC, Wideman GL. The fallacy of simple uterine curettage. Obstet Gynecol. 1958;12(6):642-8.
4. Sheth SS, Nerukar NM, Mangeshkar PS. Hysteroscopy in abnormal uterine bleeding. J Obstet Gynecol India. 1990;40:451.

5. Panda A, Parulekar SV, Gupta A. Diagnostic hysteroscopy in abnormal uterine bleeding and its histopathological correlation. J Obstet Gynecol India. 1999;175:74-6.

6. Kumaresan S, Perumal D. A clinical study of diagnostic hysteroscopy in abnormal uterine bleeding and its histopathological correlation. Int $\mathrm{J}$ Reprod Contracept Obstet Gynecol. 2018;7:396- 400.

7. Lewis BV. Hysteroscopy for the investigation of abnormal uterine bleeding. BJOG: An Int J Obstetr Gynaecol. 1990;97(4):283-4.

8. Cohen MR, Paul W. Modern hysteroscopy: Diagnostic and therapeutic potential. Fertil Steril. 1973;12:905-11.

9. Clark TJ, Mann CH, Shah N, Song F, Khan endometrial biopsy in the diagnosis of endometrial cancer: a systematic quantitative review. Br J Obstet Gynecol. 2002;109:313-21.

10. Motashaw ND, Dave S. Diagnostic and therapeutic hysteroscopy in the management of abnormal uterine bleeding. J Rep Med. 1990;35(6):616-20.

11. Kathuria R, Bhatnagar BE. Correlation between D and C, USG and hysteroscopy findings in diagnosing a cause for abnormal uterine bleeding. Indian $\mathbf{J}$ Clinic Pract. 2014;25(5):466-70.

12. Mencaglia L, Perino A, Hamou J. Hysteroscopy in perimenopausal and postmenopausal women with abnormal uterine bleeding. J Reprod Med. 1987;32(8):577-82.

13. Kumaresan S, Perumal D. A clinical study of diagnostic hysteroscopy in abnormal uterine bleeding and its histopathological correlation. Int J Reprod Contracept Obstet Gynecol. 2018;7:396-400.

14. Baggish MS, Barbot J, Valle RF. Diagnostic and operative hysteroscopy: a text and atlas. Mosby Inc; 1999.

\section{Cite this article as: Shivanagappa $\mathrm{M}$,}

Veerabhadrappa VK, Mahesh M. Diagnostic role of hysteroscopy in abnormal uterine bleeding: a comparative study of hysteroscopy findings with histopathology from Mysore, South India. Int J Reprod Contracept Obstet Gynecol 2019;8:398-401. 